\title{
Mimetismo e metamorfose
}

\author{
[ Mimicry and metamorphosis
}

\section{Larissa Costa da Mata ${ }^{2}$}

RESUMo Este texto aborda a dança na série "Os gatos de Roma / Notas para a reconstrução de um mundo perdido" (I957/I958) de Flávio de Carvalho (I899-I973) à luz da filosofia nietzschiana e das considerações de Roger Caillois (I9I3-I978) sobre o mimetismo em $\mathrm{O}$ mito e o homem (I938). Em Caillois e em Carvalho, o mimetismo propõe uma alternativa à mimese ao produzir uma instância comum entre a arte e a ciência e ao aproximar elementos tão distantes quanto o corpo e o ambiente. Na transformação mimética e na dança, o sujeito se oferece no trânsito entre si e o outro, o seu organismo e o meio. Esta reflexão também sugere uma leitura do "Ensaio sobre o ritual da serpente" (I923) de Aby Warburg (I866-I929) a partir da hipótese de que os três intelectuais compartilharam uma visão do primitivo como dança, como um instante prestes a emergir na forma de pathos e de enfermidade. • PalaVrasCHAvE Flávio de Carvalho; Dança. Mimetismo; Primitivismo - ABSTRACT This paper discusses the role of dance on "Cats from Rome / Notes for the Reconstruction of a Lost World" (I957/I958), by Flávio de Carvalho (I899-I973), in the light of Nietzsche's philosophy and mimecry theory as developed by Roger Caillois (I9I3-I978) on Myth and Man (1938). For Caillois and Carvalho, mimicry proposes an alternative to mimesis by producing a common instance between art and science and relating elements so distinctive as body and environment. Both in mimetic transformation and in dance, the subject is offered in transit from himself/herself to the other, from his/her body to space. In addition, this reflection suggests an interpretation of "A Lecture on Serpent Ritual” (I923) by Aby Warburg (I866I929), considering the hypothesis that they all shared a perspective of "primitive" as dance, or an instant likely to emerge soon, as pathos and illness. - KEYwords Flávio de Carvalho; Dance; Mimicry; Primitivism.

Recebido em Io de setembro de 2014

Aprovado em 06 de dezembro de 2014

MATA, LaRIsSa Costa. Mimetismo e metamorfose. Revista do Instituto de Estudos Brasileiros, Brasil, n. 6I, p. IO3-I2I, ago. 2015.

DoI: http://dx.doi.org/Io.II606/issn.23I6-90IX.voi6IpI03-I2I

I Doutora em Teoria da Literatura pela Universidade Federal de Santa Catarina (UFSC, Santa Catarina, Brasil). 


\section{INTRODUÇão}

No verbete "mimetismo" da Enciclopédia italiana, Alessandro Ghigi nos mostra, a partir da tipologia estabelecida pelo entomologista francês Maurice Girard (I822-I886), que o mimetismo consiste na imitação, de caráter defensivo, agressivo ou mesmo sem finalidade, da cor ou da forma do ambiente. A imitação da cor do ambiente se dá por meio dos movimentos dos cromatóforos estimulados pelas impressões visuais e pela intensidade da luz sobre um animal, geralmente escuro, que se transforma temporariamente em outro. Essa propriedade de metamorfose temporária ignora a distinção entre o ser vivo e o meio e nos faz questionar o estatuto de critérios estagnantes de interpretação do texto e dos seres - como a semelhança, a origem, a identidade, a pureza - ao criar uma instância comum entre a arte e a ciência ${ }^{\mathrm{I}}$.

O intelectual francês Roger Caillois investigara, na cópula do louva-a-deus (em "O louva-a-deus religioso", publicado pela primeira vez na revista Minotaure), a presença de um instinto de afetividade compartilhado com o homem. Prosseguindo com as pesquisas sobre as sociedades dos insetos, em "Mimetismo e psicastenia lendária", refuta as hipóteses evolucionistas de que o mimetismo consistiria em uma estratégia de sobrevivência, ao interpretá-lo como um sintoma da esquizofrenia. Os dois textos pertencem a $\mathrm{O}$ mito e o homem, de $1938^{2}$, livro escrito contemporaneamente às preliminares do Collège de Sociologie - fundado em I937 por Roger Caillois, Georges Bataille e Michel Leiris, que se reuniam no Latin Quarter Café em Paris e contavam frequentemente com a participação de Walter Benjamin³. Portanto, as reflexões de Caillois têm início nesse momento de transição entre as reuniões do Collège, nas quais se debatiam as diversas manifestações de uma sociologia do sagrado e do poder, e a

I GHIGI, Alessandro. Mimetismo. Enciclopedia Italiana di Scienze, Lettere ed Arti. Istituto della Enciclopedia Italiana, Fondata Giovanni Treccani, Roma, Istituto Poligrafico dello Stato, v. XXIII, I95I, p.338-339.

2 Neste texto, nos utilizamos da edição portuguesa: CAILLOIS, Roger. O mito e o homem. Tradução de José Calisto dos Santos. Lisboa, Edições 70, s.d.

3 Para mais informações sobre o Collège de Sociologie, ver: HOLLIER, Denis (org.). Le Collège de Sociologie I937-I939. Paris, Gallimard, I995 (Folio Essais). 
chegada desse intelectual à Argentina a convite de Victoria Ocampo ${ }^{4}$, com passagem pelo Brasil.

As ideias de Caillois acerca do mimetismo serão difundidas e ampliadas pelo artista brasileiro Flávio de Carvalho na série "Os gatos de Roma / Notas para a reconstrução de um mundo perdido", publicada entre os anos de I957 e I958 no Diário de S. Paulo ${ }^{5}$. Ambos passaram a manter uma relação de amizade e de trocas intelectuais a partir de I934, quando se encontraram no Congresso de Psicotécnica em Praga. Após esse evento, o brasileiro irá entrevistar o autor de $O$ mito e o homem 6 e tornar-se, além disso, o representante da revista Minotaure no Brasil7.

A dança está presente na obra do artista brasileiro desde o princípio e perpassa os mais diversos campos - o desenho, a dramaturgia e a cenografia ${ }^{8}$-, além dos escritos teóricos, como a série mencionada e A moda e o novo homem (20I0). Como veremos, os textos "O bailado e o crime" (I 4 de abril de I957) e "Os maleáveis bailarinos do destino" (20 de julho de I958), de "Os gatos de Roma / Notas para a reconstrução de um mundo perdido", recuperam uma dimensão da dança como enfermidade característica, para o autor, das performances do homem primitivo e das danças espanholas, como a seguidilla e o fandango. O mimetismo seria uma das estratégias adotadas por esse bailarino primitivo, que dança antes do aparecimento da linguagem, escrevendo com o próprio corpo a memória da espécie e mesclando-se ao meio em atitude de defesa. Nesses termos, o primitivo deixa de possuir o sentido de um modelo a ser imitado e passa a consistir em uma potência heterogênea na qual coexistem um passado sempre latente e uma forma de identificação entre dois seres distintos, oculta pela aparência e oferecida no ato da metamorfose.

Por sua vez, é possível associar o mimetismo (presente no ritual da serpente dos indígenas Hopi norte-americanos, analisado por Aby Warburg no "Ensaio sobre o ritual da serpente", conferência de I923) a uma concepção de representação que se constitui pelo choque entre realidades e imagens diversas e de História que se

4 Conforme destaca Raúl Antelo em Roger Caillois: magia, metáfora, mimetismo. Boletín de Estética, ano V, n. Io, p. 5-34, jun. 2009.

5 Esses textos foram publicados entre 6 jan. I957 e 2I set. I958 e podem ser localizados no Arquivo Público do Estado de São Paulo, na capital paulista.

6 A entrevista com Roger Caillois é publicada no dia 1o set. I935, no Diário de S. Paulo, com o título "Ciência e lirismo: entrevista com Roger Caillois”, e depois transcrita por Rui Moreira Leite no catálogo Flávio de Carvalho. São Paulo: Museu de Arte Moderna de São Paulo, 2010.

7 É possível localizar, no Centro de Documentação Alexandre Eulálio (CEDAE), na Universidade de Campinas, uma carta assinada por Albert Skiria (enviada de Paris, com data de 4 jan. I935) convidando Flávio de Carvalho a tornar-se o representante da Minotaure no Brasil e lhe concedendo $30 \%$ dos lucros das revistas vendidas nacionalmente.

8 A partir da década de I920, Flávio de Carvalho faz ilustrações de apresentações de balé para a imprensa paulista, em periódicos como o Jornal da Tarde, o Diário de S. Paulo e o Estado de São Paulo, nos quais estampou os desenhos dos bailados de Loïe Fuller, de Miss Hughs, Chinita Ullman e Carleto Thieben e de Josephine Baker. Em I933, estreia a peça O bailado do deus morto no Teatro da Experiência e, em I95I, planeja o cenário do espetáculo do Grupo Experimental de Ballet, com coreografia de Dorinha Costa. 
caracteriza pela permanência dos gestos impuros provenientes do passado. $\mathrm{O}$ texto mencionado relata a viagem de Warburg aos Estados Unidos de I895 a I896 e consiste na conferência que apresentara no sanatório de Kreuzlingen — onde fora interno de Ludwig Binswanger (I88I-I966) com um diagnóstico que oscilava entre psicose e esquizofrenia - para provar a sua sanidade. Publicado pela primeira vez em inglês no Journal of the Warburg and Courtauld Institutes, de I938-I939, no ensaio se instalam os sintomas do autor como um "gesto emotivo" (pathosformel), demonstrando que nem mesmo o pensamento pode estar imune à loucura. Como veremos, Warburg emprega o que supostamente consistiria em traços da sua enfermidade (a desintegração do olhar, a metamorfose do sujeito no meio) como método de análise cultural e os detecta, ao mesmo tempo, nos rituais observados.

\section{UM SABER EM COMUM}

A reflexão sobre o mimetismo sugerida por Caillois será levada às últimas consequências na série de escritos de Carvalho, na qual a transgressão dos limites (disciplinares, do corpo, do sujeito) operada por tal propriedade se remete a uma dimensão "inatual" da modernidade que não compreende a distinção entre agente e sujeito da experiência. Como consequências desse efeito de ruptura da unidade psíquica do sujeito, surgem o mimetismo — aspecto também presente na concepção dionisíaca da dança, que desagrega o princípio de individuação em favor da união telúrica - e as figurações do saber como contato. Por ser compreendido na passagem pela biologia, pela antropologia e pela psicanálise, o mimetismo se torna um recurso que opera as desterriorializações do ser, do meio e dos diversos saberes.

$\mathrm{Na}$ filosofia nietzschiana, a dança não somente alude a uma metáfora para a indistinção entre arte e filosofia, mas também a uma concepção das diversas formas de arte como dança, como o historiador da arte Georges Didi-Huberman teria observado, pautando-se em Warburg e no filósofo alemão. Todo pensamento sobre a arte também tocará os domínios da estésica: o atravessamento do corpo por sensações, pelos afetos ${ }^{\text {Io }}$. Nos textos de I957/I958, a dança emerge com a encenação do teatro dionisíaco e se torna a condição para o homem avançar em uma marcha titubeante, boba, de "movimentos oscilatórios". Portanto, a antiguidade como figuração do "começo" e o primitivo (o louco, a criança, o homem natural) se confundem nos textos que discorrem sobre as etapas do homem na "arqui-origem". Esse "tempo outro" retornará irregularmente nos reaparecimentos do homem do começo nas performances das danças espanholas, como veremos na próxima seção, perfazendo

9 WARBURG, Aby. A Lecture on Serpent Ritual. Tradução de W. F. Mainland. The Journal of the Warburg and Courtauld Institutes, v. II, p. 277-292, I938-I939. Nesse texto optei por citar a tradução para o espanhol, visto ter localizado nessa versão passagens que não se encontravam no texto em inglês. WARBURG, Aby. El Ritual de la Serpiente. Tradução de Joaquín Etorena Homaeche. México, Sextopiso, 2004.

Io DIDI-HUBERMAN, Georges. El Bailaor de Soledades. Tradução de Dolores Aguilera. Valência, Pre-Textos, 2008. 
um vínculo entre a estética e a necessidade que estará presente em diversos textos do artista brasileiro.

A gaia ciência de Nietzsche defende um saber alegre, bufão, que pertence aos insensatos e ao mimetismo do jogo de máscaras do artista. É um conhecimento que parte do instinto e que nos invade porque, assim como a memória também se compõe do esquecimento, o saber é aquilo com o qual nos deparamos quase sem querer. Inteliggere é somente a ínfima ponta do iceberg que flutua na nossa consciência ${ }^{\text {II }}$. É, justamente, porque reconhece que o saber se compõe da intuição e do esquecimento que Nietzsche emprega a metáfora da dança para tratar de um pensamento livre, desobrigado com as instituições. Essa ideia atravessa a série de I957/I958, pertencente a um gênero híbrido que poderíamos denominar de "ficção-teórica", pois nela os textos se costuram mesclando irregularmente os aparecimentos da ficção sobre o mundo perdido, criada pelo autor, a uma infinidade de textos alheios, citações soltas de fontes que se vinculam a ciências diversas (Melanie Klein, Sigmund Freud, Friedrich Nietzsche, Angelo Mosso, Charles Darwin etc.) incorporadas à série sem o que poderíamos denominar de "rigor científico".

Ora, Carvalho procurara dar, anos antes, um "nome" a essa ciência híbrida, que desbordou na década de I950. Em "A única arte que presta é a arte anormal", conferência de I936 publicada no Diário de S. Paulo naquele ano, refere-se aos domínios de uma nova ciência, a "psicoetnografia", em consonância com o surrealismo etnográfico e dissidente àquela a que pertenceram os intelectuais Roger Caillois, Georges Bataille e Carl Einstein ${ }^{\mathrm{T} 2}$. Nas “Notas”, há mais do que uma combinação entre a psicanálise e a antropologia, pois também a filosofia, a estética, a história e a ficção encontram-se implicadas. Portanto, tais escritos fazem com que surja novamente um domínio do pensamento que alude a um passado possível, avesso às instituições, no qual a distinção entre as disciplinas ainda não estava definida. É como se, nessa reinvenção do não-gênero textual e do saber antes das classificações, o autor recuperasse uma potência de transformação na estrutura que denota aos textos ao atribuí-los uma forma movente que se manifesta de maneiras diversas: vestindo máscaras, ocultando nomes e clamando outros, desconhecendo obras e justapondo fragmentos, citações soltas, com aspas completa ou parcialmente omitidas ${ }^{\mathrm{I} 3}$.

Por sua vez, Roger Caillois, em $O$ mito e o homem, opunha-se ao que supunha ser o congelamento das ciências humanas e a uma concepção autônoma da literatura, por isso, sugere um alargamento da função fabulatória do mito e da literatura, bem como da magia, para a realidade. "Mimetismo e psicastenia lendária" se inicia com uma epígrafe cujo autor não é citado, um alerta para o que virá a seguir: "Toma

II NIETZSCHE, Friedrich. A gaia ciência. Tradução de Paulo César de Souza. 5. reimp. São Paulo, Companhia das Letras, 200I.

I2 CARVALHO, Flávio Rezende de. A única arte que presta é a anormal. Diário de S. Paulo, 24 set. I936. Transcrito por Valeska Freitas e novamente publicado em: MATTAR, Denise (Curadora). Flávio de Carvalho. Ioo anos de um revolucionário romântico. Rio de Janeiro, CCBB/MAB-FAAP, I999, p. 7I-73.

I3 Reconheço, naturalmente, que parte disso se deva a equívocos comuns de digitação que poderiam ser atribuídos ao próprio autor ou à tipografia do Diário de S. Paulo. 
cuidado: brincando aos fantasmas podemos nos transformar num" ${ }^{\text {"4 }}$. Desse modo, o mimetismo aparecerá como a propriedade que nos revela o engano do olhar, o fato de que, assim como os insetos, os indivíduos são projeções no mundo, os atores de um drama. A partir de Paul Vignon, Caillois percebe que o ser que imagina se situa para além do espaço, ultrapassando os limites do corpo. Isso demonstra, segundo Vignon, que a tendência à uniformização entre as substâncias de matérias diversas equivale a uma lei fundamental do universo. $\mathrm{O}$ mimetismo também pode funcionar como o instinto, um movimento que conecta a necessidade fisiológica à finalidade de apaziguamento que o instiga. Desse modo, refere-se às operações próprias do conhecimento, importando mais o caminho percorrido do que os efeitos buscados.

\section{MiMETISMO, DANÇA E SEMELHANÇA}

Ao abolir a distinção entre a realidade e a imaginação, o mimetismo nos propõe uma formulação alternativa da identificação entre os seres, que não se pauta simplesmente em uma semelhança realista nem se oferece na superfície. Assim como a dança, compõe-se daquilo que irrompe do movimento e da potencialidade do gesto e do passe, durante a passagem da força (dionisíaca) à imagem (apolínea). Nesses termos, poderíamos compreender por que Caillois estenderá a sua reflexão em Os jogos $e$ os homens: a máscara e a vertigem (I957), definindo o mimetismo (mimicry) como estratégia de simulação teatral, a qual permitiria ao ser se transformar no herói antes visto como uma imagem do diverso - com o uso de máscaras e fantasias e em tal estado de liberdade da consciência que já não se sabe se a face vestida é a do próprio sujeito, a de Deus, ou a do herói ${ }^{15}$. Na reflexão de Caillois, na de Carvalho e na de Warburg, a representação pela arte é uma forma de contágio, o que nos obriga a rever a possibilidade de uma identidade pura e de um passado primitivo ideal.

Ora, Caillois nos mostra que o próprio ser é a máscara, a textura que se coloca sobre o ambiente. Segundo esclarece em $O$ mito e o homem, no mimetismo visual e no morfológico, a transformação engana o olhar, criando um corpo como imagem; no caso do morfológico, essa semelhança com o ambiente já não se projeta, mas faz do ser uma nova superfície e de sua imagem a de um corpo topográfico. $\mathrm{O}$ autor retoma, em sua definição, a concepção de magia simpática, definida por Sir James Frazer em O ramo de ouro, de I890. Seja do tipo imitativo ou contagioso, a magia pressupõe, para Frazer, a necessidade do contato, metafórica ou literalmente. O primeiro tipo atua tendo como princípio a semelhança entre o ato executado e o resultado esperado; já o segundo pressupõe um contato entre duas coisas que atuam entre si, mesmo au distância ${ }^{16}$. Portanto, o mimetismo pode ser compreendido como uma "metamorfose em seu ponto culminante", no qual a transformação em progresso entre dois seres,

I4 CAILLOIS, Roger, O mito..., op. cit., p. 65.

I5 CAILLOIS, Roger. Los Juegos y los Hombres: la Máscara y el Vértigo. Tradução de Jorge Ferreiro. I. reimp. México, Fondo de Cultura Económica, I994.

I6 FRAZER, James. The Golden Bough: a Study in Magic and Religion. Nova Iorque, The Macmillan Company, I945. (Abridged Edition) 
que ainda se encontram em contato, atinge o ápice, mas jamais se conclui: "O mimetismo seria, pois, a definir corretamente, como que um encantamento fixado no seu ponto culminante e tendo apanhado o feiticeiro na sua própria armadilha" ${ }^{\text {ㄱ. }}$.

$\mathrm{O}$ fenômeno foi associado por Caillois à enfermidade esquizofrênica, com base no neurologista e psicólogo francês Pierre Janet (I859-I947), autor dos estudos sobre o automatismo psicológico e a histeria: O estado mental dos histéricos (I894) e As obsessões e a psicastenia $(\mathrm{I} 9 \mathrm{O} 3)^{\mathrm{I}}{ }^{8}$. Como vemos na mesma obra de Caillois, a ação do espaço sobre os esquizofrênicos levaria a invasão mimética do meio às ultimas consequências, permitindo uma reformulação do sentido da semelhança, que deixa de pertencer à ordem da equivalência para se tornar uma potência de ser como algo ou alguém: "Ele próprio [o esquizofrênico] se sente tornar espaço, espaço negro, onde não se podem meter as coisas. É semelhante, não semelhante a algo, mas simplesmente semelhante" "I9.

Como bem sabemos, a ideia de potência está presente na dança por meio da pausa: a habilidade de conservar um movimento latente durante a interrupção. Esse aspecto não escapa a Carvalho, quem afirma, na década de I920, em um de seus comentários ilustrados de balés, que uma das falhas do espetáculo da bailarina Miss Hughs consiste em esquecer-se de que "estar parado é também uma forma de movimento" Luiz Carlos Daher, retomando o interesse de Carvalho pela dança, observa que o artista brasileiro cogitara que o termo que designa essa arte seria proveniente da palavra em sânscrito tan, equivalente a intensidade e força ${ }^{21}$. A pausa pode ser examinada segundo duas características implicadas: primeiramente, como uma memória híbrida, na qual coexistem o movimento anterior e a flexão antecipada do passo seguinte, ou seja, o instante em que o passe e o dançarino têm e não têm lugar. Já o segundo aspecto se refere ao fato de que o movimento interrompido nos leva a pensar que a semelhança entre instantes diversos, assim como a compartilhada entre dois seres, pode também ser interpretada como uma força oculta nesse corpo que está sempre à iminência de tornar-se outro. Uma simples semelhança que se oferece na relação com aquilo que (ou com quem) nos é distinto.

O termo tan, que sugere ilusão de metamorfose mimética, nos leva a considerar que, se as formas orgânicas e inorgânicas já carregam em si o gérmen do que é ser outro, não haveria porque pensarmos em origem e reprodução como meios puros, mas sempre como a passagem do um ao diverso, como mimetismo. Walter Benjamin, quem, segundo Raúl Antelo, dialogara e confrontara-se com Caillois a respeito da

I7 CAILlOIS, Roger, O mito..., op. cit., p. 79, grifo do autor.

I8 A partir de Janet, Flávio de Carvalho associa, no mundo perdido, o fenômeno da imitação à formação de laços sociais entre os homens, que se daria durante o período do "Bailado do Silêncio", uma proto-dança anterior ao desenvolvimento da linguagem e da música pelo homem. CARVALHO, Flávio Rezende de. XII Os gatos de Roma. O primeiro chefe e a floresta. Diário de S. Paulo, 3I mar. I957, p. I6.

I9 CAILLOIS, Roger, O mito..., op. cit., p. 82, grifo do autor.

20 Essa observação aparece no comentário ilustrado “Dança da Miss Hughs no Teatro Santana”, publicado em I929 no Diário de S. Paulo e reproduzido por Luiz Carlos Daher em Flávio de Carvalho: arquitetura e expressionismo. São Paulo, Projeto, I982, p. I2.

2I DAHER, Luiz Carlos. Flávio de Carvalho: a volúpia da forma. São Paulo, Edições “K”: MWM Motores, I984. 
questão, percebia o mimetismo como uma "potência virtual", por meio da qual a linguagem assumiria um comportamento mimético ${ }^{22}$. Em "A tarefa do tradutor", publicado pela primeira vez em I923, Benjamin nos esclarece que o mimetismo pode se referir a um momento arcaico em que a semelhança se dava antes do nome, antes da metáfora ou da analogia. A "habilidade" latente, no caso da linguagem, pode ser entendida como traduzibilidade, tensão imanente às diversas línguas, pois mesmo a relação entre elas no ato da tradução se oferece por meio do trânsito - nunca é estática, portanto, nem da ordem da mera equivalência. Como o mimetismo, a traduzibilidade opta pela afinidade, ou seja, por uma identificação invisível entre as línguas ou pela potência de ser "simplesmente semelhante", de modo que o que se transmite entre as formas distintas será sempre a relação pura, um contato fugidio:

Na verdade, porém, numa tradução, a afinidade entre as línguas demonstra-se muito mais profunda e determinada do que na semelhança superficial e indefinível entre duas obras poéticas. Para compreender a autêntica relação existente entre original e tradução cabe fazer um exame, cujo propósito é absolutamente análogo ao dos argumentos com os quais a crítica epistemológica deve comprovar a impossibilidade de uma teoria da cópia ou da reprodução do objeto. ${ }^{23}$

Portanto, a origem, para Flávio de Carvalho, como para Walter Benjamin, fundamenta-se na afinidade e no trânsito: ela é torvelinho, corpo bailarino, que se ergue em salto e se transforma. Por esse motivo, de acordo com a noção de começo formulada pelo autor nas “Notas para a reconstrução de um mundo perdido", a dança e o desenho são as primeiras formas expressivas do homem, pois compartilham entre si as características da mobilidade, bem como a relação intensa com o espaço em torno.

Para Friedrich Nietzsche, a dança e a música compõem os mistérios de Dioniso e o gênero trágico no princípio, com o intuito de operar as metamorfoses do divino e do espectador e de instaurar o conflito característico do momento originário. Nesse sentido, a tragédia é uma arte essencialmente anti-mimética, visto a mimese definir-se como a representação do divino no não-mutável, segundo nos mostra Massimo Cacciari em $O$ deus que baila ${ }^{24}$. A mimese está marcada por uma dimensão ontológica, na medida em que pressupunha, na filosofia platônica, a existência de um demiurgo criador que possibilita a condição da arte como verdade. A proibição do canto e da poesia sobre a qual Platão discorre em A república se refere à crise instaurada na poiesis, ao tornar o nascimento comum dessas vozes inalcançável e

22 Conforme Antelo em “A deriva mimética” e em "Roger Caillois: magia, metáfora, mimetismo”, as divergências entre ambos se devem especialmente ao fato de Benjamin crer, via Johan Jakob Bachofen, que o matriarcado poderia colocar em crise a ordem patriarcal, ao passo que Caillois resgataria o mimetismo a partir do valor da virilidade e da questão do poder, como uma força que se oporia ao Estado e à nação. ANTELO, Raúl. A deriva mimética. In: VIII Congresso Internacional da ABRALIC — Mediações, 2002, Belo Horizonte; Idem, Roger Caillois..., op. cit.

23 BENJAMIN, Walter. Escritos sobre mito e linguagem (I9I5-I92I). Organização, apresentação e notas de Susana Kampf Lages. Tradução de Susana Kampf Lages. São Paulo, Duas Cidades, 20II, p. Io7. Grifo nosso.

24 CACCIARI, Massimo. El Dios que Baila. Tradução de Virginia Gallo. Buenos Aires, Paidós, 2000. 
ao produzir efeitos de simulacros. Os simulacros, imagens esvaziadas de significado, impediriam entrever a passagem do divino à imagem no ato da criação e colocariam cada sujeito na posição indistinta de bailarino e ator, ator e espectador, como se cada um pudesse, por si só, consistir em um fenômeno estético.

Nas “Notas”, Carvalho também reforça um dinamismo originário, que surge como uma sorte de memória da qual a espécie não pode se libertar, manifestada sempre que o homem se sente impelido pela necessidade a repetir os gestos e as poses do passado. Nesse processo de "eterno retorno" da origem, o homem também se torna uma criação estética e se relaciona com o meio imitando este e os outros homens. Carvalho retoma o passado do culto do herói trágico, no seio da floresta, quando o homem estabeleceria uma relação onírica com o mundo, incapaz de discernir o sonho da realidade. Nesse mesmo período, posterior ao estágio solitário do "Bailado do Silêncio”, executado individualmente sobre as árvores, o homem primitivo não se baseia em preceitos morais ou cristãos, nem reconhece o crime contra o semelhante (por não distingui-lo propriamente como outro). O bailarino e o ator se tornam figuras equivalentes, ambos reproduzindo por meio do teatro e da dança o mundo ficcional em que vivem, o qual invade a realidade do espectador ${ }^{25}$. Os primeiros gestos que surgem são mecanismos defensivos, e a instabilidade dos movimentos reproduziria as emoções angustiantes de um período em que o medo e o ódio tornam-se indistintos, o do "homem esquizofrênico" e do "Trimestre Bobo". Para Carvalho, esse homem solitário representa um ponto antigo na escala do desenvolvimento filogenético humano em que o seu organismo era tão plástico que ora se fundia ao ambiente em busca de segurança, ora reproduzia facilmente os movimentos dos animais. São esses os "maleáveis bailarinos do Destino":

Os desequilíbrios[,] que são expressões do homem antigo e do primitivo, possuem grande adaptabilidade às situações [e] grande plasticidade. Pois se assim não fosse pereceriam por falta de capacidade de adquirir sensibilidade. São eles os maleáveis bailarinos do começo e do Destino. A plasticidade consiste em traduzir para movimentos todas as imposições do ambiente. ${ }^{26}$

\section{MIMETISMO E ESQUIZOFRENIA}

Retornemos, contudo, à primeira interpretação do fenômeno entomológico por Caillois, em "Mimetismo e psicastenia lendária”, de acordo com a qual essa propriedade, ao insinuar a invasão do sujeito pelo meio, poderia ser descrita como um dos sintomas da esquizofrenia ${ }^{27}$. No contexto em que é desenvolvida a primeira

25 CARVALHO, Flávio Rezende de. XIV — Os gatos de Roma. O bailado e o crime. Diário de S. Paulo, São Paulo, I4 abr. I957, Noticiário, p. Io.

26 Idem, LX - Notas para a reconstrução de um mundo perdido. Os maleáveis bailarinos do destino. Diário de S. Paulo, São Paulo, 20 jul. I958 p. 7. Grifo nosso.

27 O termo foi criado pelo psiquiatra suíço Eugen Bleuler (I857-I939) em I9II para descrever um grupo de 
reflexão de Caillois sobre o mimetismo, de ascensão dos Estados totalitários, o primitivo (o louco - o esquizofrênico, o histérico - ou o homem natural) é considerado na Europa uma "mancha" que nos faz recordar que a pureza, desejada pelo projeto nazista de eugenia racial, não se sustenta nem mesmo por meio da subjugação pela força, segundo comprovam as respostas formuladas pela estética, pela psicanálise e pela antropologia.

Carvalho, quem adotou uma postura sempre crítica dos acontecimentos na Europa contemporâneos à primeira etapa dessa reflexão — como a Guerra Civil Espanhola, de I936 a I938 - , na década de I950, afirma que a arte desse continente está tomada por uma tradição de beatitude e de culto ao heroísmo, bem como por um pathos cristão e que, por essa razão, necessita corroborar o dilaceramento da carne por meio da violência da guerra ${ }^{28}$. Como veremos, esse aspecto patológico, presente no mimetismo e nos textos de Flávio de Carvalho, não escapa à interpretação do ritual dos indígenas Hopi por Aby Warburg, nem às suas reflexões sobre a arte do Renascimento em A renovação da Antiguidade pagã (I932).

Vimos que nas "Notas" de Carvalho, a dança traz em si uma memória arcaica da espécie que borra a origem dos primeiros gestos ${ }^{29}$, posto não consistir em um registro da língua, mas no bailado e na mímica, anteriores à fala. Se, num tempo distante, o organismo plástico do homem se fundia ao ambiente, quando ele toma consciência do mundo ao redor e da presença do outro, formando laços sociais, os gestos adquirem um sentido distinto e o seu corpo deixa de ser tão moldável quanto antes. Com o decorrer da história e do desenvolvimento biológico do homem, somente as crianças, os esquizofrênicos e os histéricos conservaram a capacidade de repetir o bailado primitivo: seja no movimento de agarrar com as mãos (do criminoso) ou na atitude estática (dos loucos). Quando a normatividade do Estado intervém, as atitudes desse bailarino primitivo — o roubo, o assassinato — passam a ser cooptadas e rotuladas. Dessa maneira, o bailado deixa de ser um exercício de impolítica ${ }^{30}$, ou seja, de uma política que já reconhece a priori que a ambição de totalidade do Estado está fracassada, para tornar-se uma anomalia tal como a dança de São Guido,

psicoses que Emil Kraepelin (I856-I906) havia designado com o rótulo de “demência precoce", que distinguia as formas hebefrênica, catatônica e esquizofrênica. A palavra "esquizofrenia" vem do grego oxiç $\omega$ (cindir, fender) e фюńv (espírito) e procura dar conta do que Bleuler designa como sintoma preponderante dessa enfermidade, a “dissociação”. LAPLANCHE, Jean \& PONTALIS, J B. Diccionario de Psicoanálisis. Barcelona, Labor, I98I.

28 CARVALHO, Flávio Rezende de. III — Os gatos de Roma. As feridas abertas da arqueologia. O europeu quer a guerra. Diário de S. Paulo, 20 jan. I957, p. I6.

29 Essa breve definição de gesto parte da interpretação do conceito por: CASCUDO, Luís da Câmara. História dos nossos gestos. São Paulo, Global, 2003.

30 Para melhor compreender a noção de impolítico, ver o "O impolítico nietzschiano" de Massimo Cacciari em: _. Desde Nietzsche: Tiempo, Arte, Política. Tradução de Mónica B. Cragnolini e Ana Paternostro. Buenos Aires, Biblos, I994, p. 6I-80. 
enfermidade que provocava movimentos espasmódicos e se tornou uma epidemia na Idade Média ${ }^{3 \text {. }}$.

Nesse sentido, o autor recorda que o psiquiatra e antropólogo italiano Cesare Lombroso (I835-I909) acreditava que o gosto excessivo pela dança significava um indício de criminalidade ${ }^{32}$. Lombroso, autor de Gênio de loucura (I896), defendia a tese de que os criminosos pertenciam a um tipo antropológico distinto, caracterizado por atavismo, degeneração e estigmas físicos e mentais específicos. Em Gênio e loucura, analisou as produções de I07 pacientes que desenhavam e pintavam e foi o primeiro a estabelecer a relação entre os doentes mentais e o homem primitivo. Segundo $\mathrm{Hal}$ Foster ${ }^{33}$, essa analogia foi especialmente difundida entre os artistas modernos, como Paul Klee, Max Ernst e Jean Dubuffet, dentre outros, por meio de estudos no campo da arte e da psiquiatria que se baseavam, parcialmente, no discurso da degeneração instituído pelo médico italiano, bem como nas então recentes descobertas do psicanalista vienense Sigmund Freud. Podemos citar como exemplos a obra do psiquiatra alemão Hans Prinzhorn, Introdução à produção de imagens dos doentes mentais (Bildnerei der Geisteskranken, I922), e A expressão artística dos alienados (I929), escrito pelo médico psiquiatra Osório César, que conhecia o livro de Prinzhorn, a partir da observação das obras de pacientes do Hospital do Juqueri, em São Paulo34.

Para Carvalho, as sobrevivências do bailarino do começo - a criança, o criminoso e o louco - ainda conservam a insubordinação à ordem social. Nesses termos, o primitivo seria uma sorte de "falha" no desenvolvimento humano que não pôde ser apreendida pela escala evolutiva, um "sonambulismo da história”. Por outro lado, a sua distinção com relação à sociedade também pode se dar simplesmente pelo fato de não conseguir justapor a sua própria forma de organização à hegemônica. Carvalho oscila entre as duas hipóteses, de forma que afirma, nos anos I950 e, mais tarde, na defesa das teses das "Notas" no congresso Homem e Civilização: controle da mente (Universidade da Califórnia, I962), que a condição marginal da loucura pode representar um sinônimo de liberdade, ainda que involuntariamente obtida, posto remeter a um começo quando a hierarquia ainda não estaria estabelecida entre os homens e nem a presença do chefe - ou do Estado - teria sido reconhecida pelo

3I CARVALHO, Flávio Rezende de. II — Os gatos de Roma. Vila Júlia. Sonambulismo da História. Diário de S. Paulo, I3 jan. I957, p. I6.

32 Idem, XIV — Os gatos de Roma. O bailado e o crime, op. cit., p. Io.

33 FOSTER, Hal. Prosthetic Gods. Cambridge, Massachusetts/ Londres, Inglaterra, MIT, 2004.

34 Naturalmente, Flávio de Carvalho conhecia a obra de Osório César, possivelmente o livro mencionado, além de Misticismo e loucura (I930), que se encontra em sua biblioteca no CEDAE. É importante mencionar que Osório César organizou com o artista o "Mês da criança e dos loucos", que aconteceu no Clube dos Artistas Modernos em I933, evento que previa um ciclo de palestras e a exibição de obras infantis e dos artistas internos do Juqueri. Carvalho esclarece o intuito da exposição no texto publicado na revista Rumo naquele ano. Conforme SANGIRARDI JR. Flávio de Carvalho: o revolucionário romântico. Rio de Janeiro, PHILOBIBLION, I985 (Coleção Visões e Revisões, 2) e LEITE, Rui Moreira. Flávio de Carvalho (I899-I973): entre a experiência e a experimentação. Tese de doutorado, São Paulo, Universidade de São Paulo, I994. 
grupo ${ }^{35}$. Para o autor, qualquer forma de controle é contra a criatividade, ao passo que esse estágio primário de plasticidade é buscado por ele com o intuito de devolver à arte a possibilidade de renovação.

Apoiado no psiquiatra francês Maurice Dide (I873-I944), Flávio de Carvalho sustenta a ideia de que a histeria se caracteriza pela simulação das emoções e pelos movimentos espasmódicos e de contratura muscular, os quais levariam o histérico a um estágio entre a vigília e o sono, comparável ao da hipnose e ao da vida do bailarino na infância do mundo ${ }^{36}$. Para o artista brasileiro, o louco reproduz o bailado do começo ora histericamente, por meio da rigidez cataléptica dos membros e de movimentos desordenados, ora esquizofrenicamente, com a paralisia catatônica e a simulação da morte, repetida também pela criança em sono profundo. Nas "Notas", essas duas enfermidades anunciam - e coexistem com — as danças da civilização. Isso significaria, para o autor, um indício da antiguidade de danças como a seguidilla e o fandango - e mesmo da valsa vienense, do samba e da capoeira de angola ${ }^{37}$ segundo vemos em "O bailado e o crime":

A rigidez cataléptica em forma de pose estatuesca que ocorre na pausa repentina do Fandango e na Seguidilla é de natureza histérica e é uma simulação de morte repentina num momento de perigo. O Fandango e a Seguidilla são de grande antiguidade.

Na dinâmica da histeria, os movimentos de tremores, convulsões, paralisia, contrações e relaxamento flácido interrompem o plágio mimético teatral da crise de nervos e é sempre um movimento contrário que sucede ao anterior.

Seria essa interrupção a mesma pausa rígida do Fandango e da Seguidilla e uma simulação da morte e uma necessidade de defesa do organismo do homem? ${ }^{38}$

As danças espanholas andaluzas, como a seguidilha e o fandango, além do flamenco, marcam-se pela hibridez e pela profundidade dos gestos, pela contensão de cada movimento por meio da força. Israel Galván, dançarino de flamenco de que trata Didi-Huberman em $O$ dançarino de solidões, explora os "remates" e as retiradas em suas performances, alternando os momentos de intermitência (o "remate", a "simulação da morte repentina") e o ocultamento de seu corpo na escuridão,

35 De acordo com a resposta dada por Flávio de Carvalho durante o Congresso à pergunta da plateia a respeito da influência dos estados totalitários do passado e do presente na criatividade artística. CARVALHO, Flávio Rezende de. Notes for the Reconstruction of a Lost World: Age of Hunger. In: WILSON, Roger. H. L. \& FARBER, Seymour M (orgs.). Man and Civilization: Conflict and Creativity. Part Two of Control of the Mind. Nova Iorque, Universidade da Califórnia/ San Francisco Medical Center/ Mc Grill Hill, I963, p. 3I5-327. Agradeço a Rui Moreira Leite por ter me permitido consultar o seu volume dos Anais do Congresso. O texto apresentado foi traduzido ao português para o Diário de S. Paulo como "Idade da Fome. Para a reconstrução de uma idade perdida" (publicado em 22 jul. I962) e "Idade da Fome. Bailado do Silêncio" (em 29 jul. I962).

36 CARVALHO, Flávio Rezende de. XIV — Os gatos de Roma. O bailado e o crime, op. cit., p. Io.

37 Carvalho fala sobre a capoeira de angola em "Idade da Fome. Bailado do Silêncio".

38 CARVALHO, Flávio Rezende de. XIV - Os gatos de Roma. O bailado e o crime. op. cit., p. Io. 
produzindo os efeitos de montagem que caracterizam o cinema para Eisenstein ${ }^{39}$. Dançar flamenco significa partir do e retornar sempre ao solo, perder-se como pessoa no espaço e converter-se em outro (ou em outra coisa). A partir do trecho sobre a seguidilla e o fandango ${ }^{40}$, Carvalho se mostra consciente de que a interrupção do movimento já não permite que a dança seja meramente concebida como a repetição de poses idênticas. Por isso ele prossegue o fragmento citado afirmando que, sem a "simulação da morte”, "o plágio mimético continuaria se multiplicando 'ao infinito' com desdobramento de imagens, iguais e indistinguíveis" ${ }^{\text {II }}$. O corpo do bailarino primitivo introduz a diferença. Baila imperfeitamente, carregado de falhas e de terror que se transmutam em espasmos de "tremores, convulsões", pois aceita as suas particularidades e, ao mesmo tempo, faz-se a expressão de um saber inconsciente, conectando esse ser solitário a corpos e a tempos diversos. Dessa maneira, o autor demonstra uma concepção de dança que se assemelha à reprodução no espaço da dissonância musical, que podemos compreender como uma forma "não arranjada" e inconsciente, já que ocorre antes da formação precisa da melodia ${ }^{42}$.

O historiador da arte alemão Aby Warburg procurara, no "Ensaio sobre o ritual da serpente", colocar em questão o valor da pureza na arte perscrutando a presença de um vestígio patológico na ordem da representação e de um tempo híbrido — entre Atenas e Oraibi - no qual o passado se manifesta como um gesto que sobrevive no presente. Warburg vira no Barroco um período estético em que a história manifestava toda a sua intensidade, consistindo, por definição, na passagem da Antiguidade à Era Moderna. Em "Dürer e a antiguidade italiana" (I905), ele caracteriza a arte desse período pela

39 DIDI-HUBERMAN, Georges. El Bailaor..., op. cit.

$40 \mathrm{O}$ fandango e a seguidilla são marcados pela identidade híbrida, pois possuem forte influência da cultura árabe. O fandango é uma dança espanhola executada por duas pessoas em passos ligeiros, em um tempo de 3/4 ou 6/8. Possivelmente tem origem árabe e a primeira referência a ele na Espanha ocorre no início do século XVIII. As principais variações são encontradas na região da Andaluzia e levam os nomes de suas cidades, como malagueñas, de Málaga, e rondeñas, de Ronda. RAFFE, W. G. Dictionary of the Dance. Organizado por W. G. Raffe, com a assistência de M.E. Purdon. Nova Iorque/ Londres, Barns and Company, Thomas Yoseloff, I975. Por sua vez, a seguidilla é uma dança de origem espanhola-moura e o seu nome deriva das expressões seggedehiyya (entrada do povo) e seggedeh (assento, referindo-se ao estrado onde se sentam o sheik e o mulá). Equivalente à "padovana" cristã e à polonaise russo-polonesa, a seguidilla é uma dança cerimonial de entrada. Andaluza, possui ainda diferentes versões ao longo de toda a Espanha; é dançada em pares ou em grupos de casais com castanholas, com uma música em tempo de 3/4 ou 3/8. Regionalmente, leva nomes que dizem respeito à sua localidade, como as seguidillas sevillanas, além das malagueñas. Os quatro principais estilos, no entanto, são as seguidillas manchegas (vivas e alegres), as boleras (caracterizadas por movimentos lentos e momentos de fixidez), as gitanas (lentas e sentimentais) e as toleadas (caracterizadas pelo vigor) (Ibidem.).

4I CARVALHO, Flávio Rezende de. XIV — Os gatos de Roma. O bailado e o crime. op. cit., p. Io.

42 Segundo Cacciari em $O$ deus que baila, a dissonância consiste em um delírio dionisíaco ou em uma fuga da métrica musical — um modo de inserir-se fora da norma do Estado e da República, que somente poderia compreender a pureza da arte, a separação desta com relação à filosofia, embora ambas estivessem envolvidas em reproduzir e produzir efeitos de verdade, respectivamente. CACCIARI, Massimo, El Dios..., op. cit. 
violência do pathos deturpador dos gestos, das expressões faciais, que encontra o clímax em Laocoonte. Essa característica demarca a sua percepção da Renascença com a mesma transitoriedade de épocas que atribui ao Barroco e contraria a ideia de que a arte de herança clássica estivesse tomada pelo que ele denomina de "grandiosidade tranquila". Vale recordar, ainda, que Warburg se refere ao Laocoonte no "Ensaio sobre o ritual da serpente", que para ele torna-se representativo do pessimismo trágico, pois remete à morte do pai como símbolo da paixão ${ }^{43}$ ecoando a Antiguidade, além do cristianismo e do totemismo primitivo. Seja no ensaio de I905 ou bem mais adiante, em I923, vemos que os estilos também se caracterizam por representarem momentos nos quais a história atravessa as formas estéticas44.

No texto de I923, Warburg se concentra no ritual da serpente, do povoado de Walpi, resgatando esse animal como o símbolo de uma conexão mágica entre a sua aparência e a natureza. Na cerimônia descrita por ele, o animal é capturado e depois utilizado para borrar o desenho da ilustração que o simboliza, na qual aparece como raios, indicando as chuvas desejadas pelos indígenas em um procedimento de magia imitativa. Para Warburg, as serpentes, assim como os esquizofrênicos, fundem-se magicamente ao ambiente, assumindo a cor do deserto. São, além disso, seres que trocam de pele, mas permanecem os mesmos 45 . Warburg percebe nos indígenas norte-americanos a influência sofrida pelos missionários espanhóis, o que também situa os Hopi em um momento de passagem, entre a magia - que permite a atuação do contato entre dois corpos a distância — e a técnica (ou a lógica) — que reforça ainda mais a separação. Embora haja uma proximidade da civilização - por meio do uso de roupas comuns, do telégrafo, da eletricidade e das moradias sedentárias —, a magia fantástica desses indígenas representa uma enfermidade aos olhos dos europeus. Para Warburg, que nela encontra o poder de cura e de transformação e que, com o seu relato, procura provar a sanidade, consiste em um sinônimo de liberdade, não fortuitamente definida pelo historiador como uma característica do sintoma da esquizofrenia:

Aos nossos olhos, esta combinação entre magia fantástica e sóbria funcionalidade parece um sintoma de excisão; para o índio, por outro lado, isto não resulta em nada esquizofrênico, senão totalmente o contrário: é a experiência libertadora de poder estabelecer uma relação substanciosa entre o ser humano e o mundo circundante. ${ }^{46}$

Warburg, judeu e alemão, possivelmente tenha tido a integridade psicológica afetada pelo contexto em que vivia, o que o levara a anos de reclusão. Embora as causas da sua enfermidade sejam ainda obscuras e o diagnóstico impreciso, no

43 WARBURG, Aby. El Ritual..., op. cit.

44 WARBURG, Aby. Dürer and Italian Antiquity (I905). In: . The Renewal of Pagan Antiquity: Contributions to the Cultural History of the European Renaissance. Introdução de Kurt Forster. Tradução de David Britt. Los Angeles, Getty Research Institute, I999, p. 729-730.

45 WARBURG, Aby. Memories of a Journey Through the Pueblo Region: Unpublished Notes for the Kreuzlingen Lecture on the Serpent Ritual (I923). In: MICHAUD, Philippe-Alain. Aby Warburg and the Image in Motion. Tradução de Sophie Hawkes. Nova Iorque, Zone Books, 2004, p. 293-330.

46 WARBURG, Aby. El Ritual..., op. cit., p. II. Tradução e grifo nossos. 
epílogo da tradução ao espanhol do "Ensaio sobre o ritual da serpente”, Ulrich Raulff47 sustenta a tese de que o historiador sofrera os efeitos da Primeira Grande Guerra, que alterou o sistema político da Alemanha, demarcando a passagem da monarquia de Kaiser Guilherme, apoiada por Warburg, ao período de antissemitismo que culminou com o nazismo.

Poucos anos após a sua morte, em I933, e em decorrência da guerra, a biblioteca de Warburg é transferida para Londres, onde é fundado o Instituto que leva o nome dele $4^{8}$ e que se responsabiliza por publicar a conferência de I923 pela primeira vez. O "Ensaio sobre o ritual da serpente" é traduzido para o segundo número do Journal of the Warburg and Courtauld Institutes, organizado por Edgar Wind, Rudolf Wittkower e Anthony Blunt, depois de ter ficado guardado sob os auspícios de Fritz Saxl, e divulgado com a observação de que os pesquisadores do Instituto não dariam continuidade à investigação iniciada pelo autor ${ }^{4}$.

A experiência warburguiana esteve perpassada pelo contato dele com os indígenas, bem como pelos estudos da antropologia social inglesa, vertente à qual Frazer e Sir Edward Burnett Tylor pertenceram, sendo esse último o responsável pelo conceito de sobrevivência (survival) na obra de Warburg. A afinidade com essa disciplina permitiu-lhe valer-se de uma perspectiva temporal não somente delimitada pelos dados, mas também pelas marcas deixadas nos corpos, na memória. Entretanto, se observarmos as colaborações estampadas naquele periódico por discípulos como Erwin Panofsky e Ernst Gombrich entre I937 e I973, podemos concluir que, apesar de a revista se propor a criar uma instância comum entre disciplinas como a história da arte e a antropologia, esta última não é muito constante nas reflexões de ambos. Talvez por essa diversidade de interesses, Panofsky e Gombrich tenham buscado eliminar o pathos no estudo da obra de Warburg, seja este compreendido como enfermidade mental ou como força dionisíaca, que não submete o tempo a uma forma estável ${ }^{50}$.

No contexto em que as considerações sobre o mimetismo se iniciam, o antissemitismo é visto pelo regime nazista como um meio de se reconstituir uma identidade cujas chances de existência estariam de antemão eliminadas. Esteticamente, o nazismo privilegiava uma arte de aspiração clássica e mimética em detrimento das incursões de artistas modernos pela arte de doentes mentais e pelas estéticas africana, asiática ou indígena, que produziam uma arte perpassada por uma força telúrica e dionisíaca e de corpos alterados. Diversos exemplos desse conflito entre a Europa e o primitivo podem ser citados, como a Exposição Universal

47 RAULFF, Ulrich. Epílogo. In: WARBURG, Aby. El Ritual..., op. cit., p. 66-II4.

48 BURUCÚA, José Emilio. Historia, Arte, Cultura: de Aby Warburg a Carlo Ginzburg. Buenos Aires, Fondo de Cultura Económica, 2002.

49 Conforme a nota de rodapé anexada à primeira página do texto. In: WARBURG, Aby. A Lecture..., op. cit., p. 277.

50 Nesse sentido, vale recorrer ao livro A imagem sobrevivente, no qual Georges Didi-Huberman reforça o fato de que os herdeiros de Aby Warburg (dentre eles, Ernst Gombrich) teriam buscado ocultar a presença do pathos na obra do historiador da arte alemão. DIDI-HUBERMAN, Georges. L'Image Survivante: Histoire de l’Art et Temps des Fantômes selon Aby Warburg. Paris, Minuit, 2002. (Paradoxe) 
que acontece em Paris em I937 - na França subjugada por Hitler —, que recebeu polemicamente a obra Prometeu estrangulando o abutre, do lituano Jacques Lipchitz (I89I-I973), inspirada na arte africana e asiática; e a exposição "A arte degenerada", ocorrida na Alemanha naquele mesmo ano. Organizado pelo médico psiquiatra Carl Schneider, diretor da clínica de Heidelberg, esse evento procurava confrontar a "deformidade" das obras de artistas modernos e dos loucos com a ordem e a uniformidade almejadas pelo nazismo ${ }^{5 \text {. }}$.

Raúl Antelo estaria certo em sugerir, em "A deriva mimética”" mimese e mimetismo significaria uma cisão entre a Europa e a América Latina, hipótese elaborada a partir das colaborações deixadas por Roger Caillois na revista argentina Sur. De fato, ao propor uma extensão entre a imaginação e a realidade e ao perscrutar os sintomas como pertencentes à civilização, Caillois sugere-nos que a infamiliaridade atribuída aos povos primitivos e aos doentes mentais pertence, na verdade, aos ritos das instituições contemporâneas, de modo que concluirá, em $O$ homem e o sagrado, à mesma época da primeira reflexão sobre o mimetismo, que o sagrado se fundamenta na ambiguidade do impuro e que toda tentativa de restaurar a ordem é falha: não se pode recuperar a pureza primitiva nem eliminar as cicatrizes, pois qualquer forma de contato nos altera ${ }^{53}$.

O artista brasileiro compartilhava com a atitude etnográfica de Roger Caillois, Georges Bataille e Carl Einstein a percepção de que o dilaceramento é um produto da própria civilização e não uma consequência do contato com a diferença primitiva. Movido por uma atitude arqueológica, Flávio de Carvalho percebia que, como a psique humana, o mundo investigado por ele se compunha de diversas camadas de tempo e de uma história em que resistem as feridas deixadas pelas guerras. Essas feridas movimentavam um impulso bélico — ainda no presente em que lançara as considerações, o da Guerra Fria e dos conflitos no Egito - ao qual o autor fará referência nas "Notas" 54 . Nesse sentido, a presença da dança em suas reflexões como uma arte anterior à formação dos gêneros e à linguagem mesma está atrelada à compreensão do primitivo como uma força que se manifesta imprevisivelmente na escala do tempo.

5I Para melhor compreender a questão, consultar: FOSTER, Hal, op. cit.

52 ANTELO, Raúl. A deriva..., op. cit.

53 CAILLOIS, Roger. El Hombre y lo Sagrado. Tradução de Juan José Domenchina. México: Fondo de Cultura Económica, I942. A edição original é de I939.

54 A primeira parte da série se designa "Os gatos de Roma" possivelmente porque as observações desses textos surgiram da ida de Flávio de Carvalho à Itália em meados de I956, para desfilar o traje de verão e expor os seus trabalhos. De acordo com Verônica Stigger, quando o autor se encontra em Roma, a cidade estava tomada por manifestações estudantis contra a invasão da Hungria pela União Soviética e os jornais se ocupavam de outro evento político fundamental, que deixa o seu registro nas "Notas para a reconstrução de um mundo perdido": o bombardeio ao Canal de Suez, nacionalizado em julho de I956 pelo presidente Gamal Abdul Nasser. STIGGER, Verônica. Flávio de Carvalho: experiências romanas. MARCELINA. Revista do Mestrado em Artes Visuais da Faculdade Santa Marcelina. Ano 3, vol. 4, p. I09-I28, I sem. 2010 . A referência a Nasser é feita em "Ritmo e memória”. CARVALHO, Flávio Rezende de. XVII — Os gatos de Roma. Ritmo e memória. Diário de S. Paulo, São Paulo, I2 maio I957, p. I5. 
Publicadas em fins dos anos I950, as "Notas para a reconstrução de um mundo perdido", aparentemente, retomam o modernismo brasileiro em um momento em que as incursões primitivistas dessa vanguarda e das europeias soariam como fora de época e de lugar. Nesse período, o abstracionismo - movimento de vanguarda com o qual Flávio de Carvalho não demonstrou grande afinidade — passa a ser defendido por críticos brasileiros como Mário Pedrosa. Ao mesmo tempo, artistas dessa linha e concretistas recebem mais atenção em eventos como a Bienal de São Paulo de I957, da qual Carvalho tem os trabalhos excluídos 55 . Crítico das instituições acadêmicas como sempre se mostrou, possivelmente o seu empenho de realizar uma jornada "psicoetnográfica" nessa série de escritos, uma genealogia da própria arte no mundo em formação, seja condizente com a postura, por vezes marginal, relativa a instituições como a própria Bienal. No entanto, nesse momento, a retomada do primitivismo modernista por Flávio de Carvalho se oferece apenas como a repetição de um gesto, que já não é movido pela mesma finalidade desse movimento de outrora (quando o primitivo aparecia como o grau zero da nossa história), mas se insere em uma leitura mais ampla da modernidade, vinculada ao pensamento nietzschiano, segundo o qual nenhum momento é puro e a identidade se constitui somente como relação.

\section{SOBRE A AUTORA}

LARISSA COSTA DA MATA é doutora em Teoria da Literatura pela Universidade Federal de Santa Catarina. Atuou como Leitora de Cultura Brasileira e Língua Portuguesa junto à Universidade de Pequim de 2013 a 20I4.

E-mail: larissa.mata@gmail.com.

\section{REFERÊNCIAS BIBLIOGRÁFICAS}

ANTELO, Raúl. A deriva mimética. In: VIII Congresso Internacional da ABRALIC — Mediações, 2002, Belo Horizonte.

. Roger Caillois: magia, metáfora, mimetismo. Boletín de Estética, ano V, n. Io, p. 5-34, jun. 2009.

BENJAMIN, Walter. Escritos sobre mito e linguagem (I9I5-I92I). Organização, apresentação e notas de Susana Kampf Lages. Tradução de Susana Kampf Lages. São Paulo, Duas Cidades, $20 I I$.

BURUCÚA, José Emilio. Historia, Arte, Cultura: de Aby Warburg a Carlo Ginzburg. Buenos Aires, Fondo de Cultura Económica, 2002.

CACCIARI, Massimo. El Dios que Baila. Tradução de Virginia Gallo. Buenos Aires, Paidós, 2000. O impolítico nietzschiano In: . Desde Nietzsche: Tiempo, Arte, Política. Tradução de Mónica

B. Cragnolini e Ana Paternostro. Buenos Aires, Biblos, I994.

55 A lista de artistas excluídos dessa Bienal, contudo, é extensa e nela podemos incluir nomes como o de Alfredo Volpi, Carybé, Bruno Giorgi, Paulo Becker, Aldo Bonadei e Ítalo Cencini. Conforme TOLEDO, J. Flávio de Carvalho: o comedor de emoções. São Paulo/Campinas, Brasiliense/ UNICAMP, I994. 
CAILLOIS, Roger. Ciência e lirismo: entrevista com Roger Caillois. Diário de S. Paulo. Io de setembro de I935.

. El Hombre y lo Sagrado. Tradução de Juan José Domenchina. México: Fondo de Cultura Económica, I942.

. Los Juegos y los Hombres: la Máscara y el Vértigo. Tradução de Jorge Ferreiro. I. reimp. México, Fondo de Cultura Económica, I994.

. O mito e o homem. Tradução de José Calisto dos Santos. Lisboa, Edições 70, s.d.

CARVALHO, Flávio de. Os gatos de Roma / Notas para a reconstrução de um mundo perdido. Diário de S. Paulo. De 6 de janeiro de I957 a 2I de setembro de I958.

. A única arte que presta é a anormal. Diário de S. Paulo, 24 set. I936. In: MATTAR, Denise (Curadora.). Flávio de Carvalho. Ioo anos de um revolucionário romântico. Rio de Janeiro, CCBB/ MAB-FAAP, I999, p. 7I-73.

. Dança da Miss Hughs no Teatro Santana Diário de S. Paulo, I929. In: DAHER, Luiz Carlos. Flávio de Carvalho: arquitetura e expressionismo. São Paulo, Projeto, I982.

. II — Os gatos de Roma. Vila Júlia. Sonambulismo da História. Diário de S. Paulo, I3 jan. I957.

. III - Os gatos de Roma. As feridas abertas da arqueologia. O europeu quer a guerra. Diário de S. Paulo, 20 jan. I957.

. LX - Notas para a reconstrução de um mundo perdido. Os maleáveis bailarinos do destino. Diário de S. Paulo, São Paulo, 20 jul. 1958.

. Notes for the Reconstruction of a Lost World: Age of Hunger. In: WILSON, Roger. H. L. \& FARBER, Seymour M (orgs.). Man and Civilization: Conflict and Creativity. Part Two of Control of the Mind. Nova Iorque, Universidade da Califórnia/ San Francisco Medical Center/ Mc Grill Hill, I963, p. 3I5-327.

.XII — Os gatos de Roma. O primeiro chefe e a floresta. Diário de S. Paulo, 3I mar. I957.

XIV — Os gatos de Roma. O bailado e o crime. Diário de S. Paulo, São Paulo, I4 abr. I957.

XVII — Os gatos de Roma. Ritmo e memória. Diário de S. Paulo, São Paulo, I2 maio I957.

CASCUDO, Luís da Câmara. História dos nossos gestos. São Paulo, Global, 2003.

DAHER, Luiz Carlos. Flávio de Carvalho: a volúpia da forma. São Paulo, Edições “K”: MWM Motores, I984.

DIDI-HUBERMAN, Georges. El Bailaor de Soledades. Tradução de Dolores Aguilera. Valência, PreTextos, 2008.

. L'Image Survivante: Histoire de l'Art et Temps des Fantômes selon Aby Warburg. Paris, Minuit, 2002. (Paradoxe)

FOSTER, Hal. Prosthetic Gods. Cambridge, Massachusetts/ Londres, Inglaterra, MIT, 2004.

FRAZER, James. The Golden Bough: a Study in Magic and Religion. Nova Iorque, The Macmillan Company, I945. (Abridged Edition, I)

GHIGI, Alessandro. Mimetismo. Enciclopedia Italiana di Scienze, Lettere ed Arti. Istituto della Enciclopedia Italiana, Fondata Giovanni Treccani, Roma, Istituto Poligrafico dello Stato, v. XXIII, I95I, p. 338-339.

HOLLIER, Denis (org.). Le Collège de Sociologie I937-I939. Paris, Gallimard, I995. (Folio Essais).

LAPLANCHE, Jean \& PONTALIS, J B. Diccionario de Psicoanálisis. Barcelona, Labor, I98I.

LEITE, Rui Moreira. Flávio de Carvalho (I899-I973): entre a experiência e a experimentação. Tese de doutorado, São Paulo, Universidade de São Paulo, I994.

. Flávio de Carvalho. São Paulo, Museu de Arte Moderna de São Paulo, 2010. 
NIETZSCHE, Friedrich. A gaia ciência. Tradução de Paulo César de Souza. 5. reimp. São Paulo, Companhia das Letras, 200 .

RAFFE, W. G. Dictionary of the Dance. Organizado por W. G. Raffe, com a assistência de M.E. Purdon. Nova Iorque/ Londres, Barns and Company, Thomas Yoseloff, I975.

SANGIRARDI JR. Flávio de Carvalho: o revolucionário romântico. Rio de Janeiro, PHILOBIBLION, I985 (Coleção Visões e Revisões, 2).

STIGGER, Verônica. Flávio de Carvalho: experiências romanas. MARCELINA. Revista do Mestrado em Artes Visuais da Faculdade Santa Marcelina. Ano 3, vol. 4, p. Io9-I28, I sem. 2010.

TOLEDO, J. Flávio de Carvalho: o comedor de emoções. São Paulo/Campinas, Brasiliense/ UNICAMP, I994.

WARBURG, Aby. A Lecture on Serpent Ritual. Tradução de W. F. Mainland. The Journal of the Warburg and Courtauld Institutes, v. II, p. 277-292, I938-I939. . Dürer and Italian Antiquity (I905). In: . The Renewal of Pagan Antiquity: Contributions to the Cultural History of the European Renaissance. Introdução de Kurt Forster. Tradução de David Britt. Los Angeles, Getty Research Institute, I999. . El Ritual de la Serpiente. Tradução de Joaquín Etorena Homaeche. México, Sextopiso, 2004. . Memories of a Journey Through the Pueblo Region: Unpublished Notes for the Kreuzlingen Lecture on the Serpent Ritual (I923). In: MICHAUD, Philippe-Alain. Aby Warburg and the Image in Motion. Tradução de Sophie Hawkes. Nova Iorque, Zone Books, 2004, p. 293-330. 